\title{
Safety and security: a survey of female psychiatric in-patients
}

\author{
Fiona Barlow and Paul Wolfson
}

\begin{abstract}
Fifty-three female in-patients of a psychiatric hospital were interviewed to obtain their views on their own safety and securtly, and what improvements they would recommend. Most had experienced sexual harasement and a few had been victims of sexual assault. There was a reluctance to report incidents to staff. The majority felt that female-only wards would improve safety. Other recommendations included higher staffing levels, more staff awareness and vigilance, and single rooms with curtains on the doors.
\end{abstract}

There has been mounting public and professional concern about the security and safety of female inpatients on psychiatric wards (Subotsky, 1991). Explanations for women being at greater risk include staff shortages causing reduced supervision, the decline in in-patient beds creating a higher turnover of younger and more disturbed patients, and lack of resources to provide single sex facilities (Tonks, 1993). The MILMIS Report found high rates of violence and sexual harassment, and suggested overcrowding, inappropriate ward design and absence of a range of facilities to be important considerations (MILMIS Project Group, 1995). The Royal College of Psychiatrists published a statement in 1989 on sexual abuse and harassment of in-patients (Gath, 1989). It recommended sexual education, counselling, contraceptive advice and staff training.

Although policies have been developed for inpatients (for example Subotsky, 1993), a recent study of actual and perceived safety of psychiatric in-patients in an inner London hospital revealed that $71 \%$ reported unwanted physical and sexual experiences, with female patients experiencing a significantly higher incidence of minor and serious sexual victimisation (Thomas et al, 1995). The Patients' Charter has now incorporated the right of female patients to be admitted to female-only wards (Department of Health, 1995) but extra resources will not be made available to implement this.

\section{The study}

This study set out to obtain the views of female in-patients of a psychiatric hospital on the safety and security and what improvements they would recommend.

During a two-month period, female in-patients of two acute and four rehabilitation wards in a large psychiatric hospital were interviewed by a female psychiatrist not involved in their treatment. On these wards there was a total of 180 patients, of whom 90 were female. Those considered by the ward staff to be too ill to be interviewed were excluded. A semi-structured questionnaire, which had been approved by the local research ethics committee, was used. Each patient gave written informed consent. Demographic details and diagnostic category were recorded. Their opinions were asked on preference for single sexed wards, female staff only, HIV education, avallability of condoms, and their experiences of harassment and sexual assault.

\section{Findings}

Of a total of 90 female in-patients on the wards surveyed, 53 were identified as available for interview and judged by the ward team to be able to give informed consent. Only 50 women were interviewed as two refused and one was unable to complete the interview. Thirty-four of those interviewed were from acute wards and 16 from rehabilitation wards. The mean age was 43 years (range 21-68), 45 were white, four were of Afro-Caribbean origin and one of African origin. Fifteen were detained on a section of the Mental Health Act.

The median duration of stay for those on acute wards was 31.7 days and on rehabilitation wards was 46 months. Seventy per cent of the women shared a dormitory, $22 \%$ had their own room and $8 \%$ shared a room with another woman.

Table 1. Preferences for female only services

\begin{tabular}{llll}
\hline & Yes & No & $\begin{array}{l}\text { Don't } \\
\text { mind }\end{array}$ \\
\hline Preference for female only wards & $52 \%$ & $16 \%$ & $32 \%$ \\
Preference for female only staff & $14 \%$ & $58 \%$ & $28 \%$ \\
Preference for female keyworker & $42 \%$ & $14 \%$ & $40 \%$ \\
\hline
\end{tabular}


Half the women $(52 \%)$ wanted female only wards (Table 1). The commonest reasons were that the women would feel safer, have more privacy and not be subject to sexual harassment from male patients. Fifty-eight per cent did not want female only staff. They felt safer with male nurses on duty and some felt male staff were more understanding. Forty-two per cent preferred a female keyworker because they felt women can relate better to women's problems, but a similar percentage had no preference.

Fourteen per cent of women had been sexually active while an in-patient. Sixteen per cent had never heard of HIV or AIDS, including seven out of the 16 patients from rehabilitation wards; $32 \%$ wanted more information about HIV but $68 \%$ did not. They felt it did not affect them, either because they were in a stable relationship or had no partner. The majority of the whole group $(84 \%)$ preferred the source of information to be the ward doctors and nurses rather than a health worker from outside. Sixty per cent thought condoms should be available on the wards but a substantial minority (36\%) did not. Reasons given why condoms should not be available included that it encouraged sexual intercourse between patients and also that a psychiatric hospital is not the right setting to have a sexual relationship.

Over half the women (56\%) had been pestered. including 11 of the patients from rehabilitation wards (see Table 2). Examples of pestering were being touched on legs, breasts or bottom, male patients pushing up behind them in the dinner queue, being constantly asked to have sex by a patient from another ward, and male patients walking into the female dormitory at night. Four of the 16 patients from rehabilitation wards had taken part in a sexual act against their will, either with another patient or a visitor. These acts took place in empty corridors or in the hospital grounds, not on the wards. Twelve per cent of all the women had been asked to have sexual intercourse for favours, for example cigarettes, money or alcohol. The majority of women did not report their experiences to staff. However, those who did were mostly satisfied with the staff response. Three male in-patients were responsible for the majority of incidents.

All those interviewed were asked for their own recommendations to improve the safety and security of female in-patients, (see Table 3). The commonest recommendation was female only wards $(42 \%)$. Others concern staff attitudes, staffing levels and architectural/design features. However, $22 \%$ did not believe there should be any changes.

\section{Comment}

The vulnerability of women, especially on rehabilitation wards, to being asked to have intercourse for favours and sexual assault is of great concern. The women were reluctant to disclose these matters to staff because they feared they would not be believed, there might be reprisals, and they would suffer the embarrassment and shame of legal proceedings. Some believed it was due to the perpetrator's mental illness that they had been pestered and therefore did not report the incidents.

Table 2. Patients' experiences of sexual harassment and assault

\begin{tabular}{llll}
\hline During their hosplital stay had: & $\begin{array}{l}\text { Overall } \\
(\%)\end{array}$ & $\begin{array}{l}\text { Acute wards } \\
(\mathbf{n}=\mathbf{3 4})\end{array}$ & $\begin{array}{l}\text { Rehabilitation wards } \\
(\mathbf{n}=16)\end{array}$ \\
\hline Been pestered by men in any way & 56 & 17 & 11 \\
Done anything sexually against their will & 8 & 0 & 4 \\
Been asked to have sex for favours, e.g. cigarettes & 12 & 2 & 4 \\
Reported their experiences to members of staff & 39 & 11 & 4 \\
\hline
\end{tabular}

Table 3. Female patients' recommendations to improve safety and security

Female only wards.

Nursing staff should be more aware of male patients who make advances to female patients. More staff to reduce feeling threatened.

More nurses at night to check who goes in and out of the dormitory.

Every patient should have their own room.

There should be curtains on all the bedroom doors.

A mother and baby unit should be attached to the ward.

More female only activities, e.g. keep fit, swimming and arranged walks. 
The finding that nearly half the women on rehabilitation wards had no understanding of HIV and AIDS raises the question of who is responsible for their sexual education and ultimately their health and welfare.

The preference of the majority of women for female only wards indicated a need to feel safe from sexual harassment rather than a wish to return to the strict segregation of years ago. However, this measure alone would be unlikely to reduce the incidence of sexual assault which occurred away from the ward in the long empty corridors or in the hospital grounds. Clear, well understood policies on sexual matters, staff training, patient education and provision of counselling are extremely important, but so are the more structural changes recommended by the women themselves.

Wherever people meet or live together, sexual abuse and harassment will occur. On a psychiatric ward there is a difficult balance between ensuring that people have the right to enjoy a sexual relationship and protecting them from exploitation. The wider issue that needs to be addressed is whether people who are in hospital to protect the public from their sexual behaviour should be living in close proximity to people who may be in hospital precisely because they are sexually vulnerable.

\section{References}

DEPARTMENT OF HEALTH (1995) The Patients' Charter and You. London: HMSO.

GATH, A. (1989) Statement on abuse and harassment within psychiatric hospitals. Psychiatric Bulletin, 13, 460.

MILMIS PROSECT GROUP (1995) Monitoring inner London mental illness services. Psychiatric Bulletin, 19. 276-280.

SUBOTSKY. F. (1991) Issues for women in the development of mental health services. British Joumal of Psychiatry. 159 (suppl. 10), 17-21.

- (1993) Sexual abuse in psychiatric hospital: developing policies to ald prevention. Psychiatric Bulletin, 17, 274-276.

Thomas, C., BARTLETt, A. \& MEZEY, G. C. (1995) The extent and effects of violence among psychlatric inpatients. Psychiatric Bulletin, 19, 600-604.

TONKS, A. (1993) Women patients vulnerable in mixed psychiatric wards. British Medical Journal, 304, 1331.

*Fiona Barlow, Senior Registrar, Lennard Lodge Child and Family Psychiatry Clinic, 3 Lennard Road, Croydon CRO 2UL; and Paul Wolfson, Consultant Psychiatrist, Bexley Hospital, Kent DA5 2BW

*Correspondence

\title{
Psychological Trauma - A Developmental Approach
}

\author{
Edited by Dora Black, Martin Newman, Jean Harris Hendriks and Gillian Mezey
}

This is the first UK textbook on psychological trauma and contains contributions by many of the country's leading authorities on responses to traumatic events. It is edited by four clinicians with extensive experience on this subject.

The book discusses normal and abnormal responses to stress, disasters, war and civil conflict, and interpersonal violence, diagnosis, interventions and treatments, and legal aspects. There is reference throughout to the research findings, and discussion of future research needs. Each chapter contains a comprehensive bibliography for those who wish to read further. Published January 1997, price £30.00, 424pp. ISBN 0902241982

Gaskell is the imprint of the Royal College of Psychiatrists. Gaskell books are available from good bookshops and from the Publications Department, Royal College of Psychiatrists, 17 Belgrave Square, London SW1X 8PG (Tel. +44(0)171 235 2351, extension 146). The latest information on College publications is available on the INTERNET at: http://www.demon.co.uk/rcpsych/

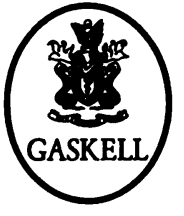

